\title{
Diversity of Fungal Endophytes in Various Tissues of Panax ginseng Meyer Cultivated in Korea
}

\author{
Young-Hwan Park ${ }^{1}$, Soon-Gu Lee ${ }^{2}$, Doek Jong Ahn ${ }^{3}$, Tae Ryong Kwon ${ }^{3}$, Sang Un Park ${ }^{4}$, \\ Hyoun-Sub Lim ${ }^{5}$, and Hanhong Bae ${ }^{1^{*}}$
}

${ }^{1}$ School of Biotechnology, Yeungnam University, Gyeongsan 712-749, Korea

${ }^{2}$ School of Bioresource Science, Andong National University, Andong 760-749, Korea

${ }^{3}$ Punggi Ginseng Experiment Station, Gyeongbuk Provincial Agricultural Research \& Extension Services,

Yeongju 750-870, Korea

${ }^{4}$ Department of Crop Science, Chungnam National University, Daejeon 305-764, Korea

${ }^{5}$ Department of Applied Biology, Chungnam National University, Daejeon 305-764, Korea

Endophytic fungi were isolated from various tissues (root, stem, petiole, leaf, and flower stalk) of 3- and 4-year-old ginseng plants (Panax ginseng Meyer) cultivated in Korea. The isolated endophytic fungi were identified based on the sequence analysis of the internal transcribed spacer (ITS), 1-5.8-ITS 2. A morphological characterization was also conducted using microscopic observations. According to the identification, 127 fungal isolates were assigned to 27 taxa. The genera of Phoma, Alternaria and Colletotrichum were the most frequent isolates, followed by Fusarium, Entrophospora and Xylaria. Although 19 of the 27 taxa were identified at the species level, the remainder were classified at the genus level (6 isolates), phylum level (Ascomycota, 1 isolate), and unknown fungal species (1 isolate). Endophytic fungi of 13 and 19 species were isolated from 3-and 4-year-old ginseng plants, respectively, and Phoma radicina and Fusarium solani were the most frequently isolated species colonizing the tissues of the 3- and 4-year-old ginseng plants, respectively. The colonization frequency (CF\%) was dependant on the age and tissue examined: the CFs of the roots and stems in the 3-year-old ginseng were higher than the CF of tissues in the 4-year-old plants. In contrast, higher CFs were observed in the leaves and petioles of 4-year-old plants, and endophytic fungi in the flower stalks were only detected in the 4-year-old plants. In conclusion, we detected diverse endophytic fungi in ginseng plants, which were distributed differently depending on the age and tissue examined.

Keywords: Panax ginseng, Endophytic fungi, Internal transcribed spacer, Fungal distribution

\section{INTRODUCTION}

Ginseng, Panax ginseng Meyer, is a perennial plant of the Araliaceae family and has been used for thousands of years as an important medicinal plant. Ginseng contains various pharmacologically active ingredients, including ginsenosides, phenols, oleanic acids and volatiles [1]. Ginseng saponins, also known as ginsenosides, have a

(cc) This is an Open Access article distributed under the terms of the Creative Commons Attribution Non-Commercial License (http://creativecommons.org/licenses/by-nc/3.0/) which permits unrestricted non-commercial use, distribution, and reproduction in any medium, provided the original work is properly cited. specific chemical structure compared to the saponins of other plants and have different, extensive effects as antitumor, antidiabetic and antioxidant compounds and as cholesterol-reducing agents [2-5]. The growth of ginseng plants requires 4 to 6 years of cultivation under shaded conditions, and ginseng cultivation is affected by the soil

Received 17 Jun. 2011, Revised 26 Nov. 2011, Accepted 26 Nov. 2011

*Corresponding author

E-mail: hanhongbae@ynu.ac.kr

Tel: +82-53-810-3031, Fax: +82-53-810-4769 
environment due to the long cultivation period in the same soil [6]. One major problem is the complication of disease caused by different pathogenic fungi during the long cultivation period. The most common pathogenic fungi in ginseng include gray mold by Botrytis cinerea, alternaria blight by A. panax, anthracnose by Colletotrichum gloeosporioides, Sclerotinia white rot by Sclerotinia sp., phytophthora blight by Phytophthora cactorum, and root rot by Cylindrocarpon destructans $[7,8]$. Therefore, the control of these types of diseases is of great importance to ginseng growers.

The recent investigation of fungi that exist in plants as symptomless endophytes has shed light on many aspects of the relationships between the plant and fungus [9]. Endophytic fungi usually do not directly penetrate plant cells; instead, they grow as relatively sparse hyphae in the spaces between cells or within the walls of the host plant cells. Endophytic fungi spend all or part of their life cycle in the host consuming nutrients from the intercellular fluids of the plants $[10,11]$. Some endophytic fungi produce a wide range of bioactive compounds that have commercial potential as important compounds for medicinal, agricultural and industrial purposes $[9,12,13]$, such as alkaloids, steroids, terpenoids, isocoumarin derivatives, quinones, flavonoids, and lignans. These compounds have diverse functions in plants, such as in protection against phytopathogens and the promotion of growth, which occurs due to the production of such phytohormones as auxin and gibberellins and the absorption of such nutrients as nitrogen and phosphorus from the soil $[11,14]$. However, there are only a few reports on the fungal endophytes present in ginseng $[12,15,16]$. Therefore, this study was conducted to explore the diversity of the endophytic fungi in plants of different ages and different tissues of $P$. ginseng cultivated in Korea.

\section{MATERIALS AND METHODS}

\section{Harvest of ginseng plants}

Ginseng plants ( $P$. ginseng) that were 3- and 4-years old were harvested from Punggi Ginseng Experimental Station (Yeongju, Korea) in July 2010. Six ginseng plants were used for each age as replicates. The harvested plants were placed in plastic bags and stored at $4{ }^{\circ} \mathrm{C}$ until use; the plant samples were processed within $48 \mathrm{~h}$ of the harvest.

\section{Isolation of endophytic fungi}

Ginseng plants were washed thoroughly with running water for $5 \mathrm{~min}$ to remove the soil and sediments. The plants were separated into root, stem, petiole, leaf, and flower stalk. The root, stem, petiole, and flower stalk samples were cut into $10 \times 10 \mathrm{~mm}$ segments using a sterilized blade, and the leaves were cut into $5 \times 2 \mathrm{~mm}$ segments using a sterilized blade. All of the sample segments were surface sterilized in a $75 \%$ ethanol solution for 1 min, transferred to a solution of $4 \%$ sodium hypochlorite for $10 \mathrm{~min}$, and then washed with $75 \%$ ethanol for $30 \mathrm{~s}$. The surface-sterilized samples were rinsed 3 times with sterile water for $1 \mathrm{~min}$ and blotted dry on sterile paper towels. Aliquots $(3 \times 0.1 \mathrm{~mL})$ of the water used for the last washing step were dropped into potato dextrose agar (PDA) plates amended with $200 \mathrm{mg} / \mathrm{mL}$ ampicillin and streptomycin to confirm the removal of the microorganisms from the tissue surface. The sterilized segments were placed on Petri dishes containing PDA with 200 $\mathrm{mg} / \mathrm{mL}$ ampicillin and streptomycin to inhibit bacterial growth and then incubated at room temperature for 2 to 3 wk [15]. The plates were evaluated every day until the appearance of mycelia from the edge of the sample segments. The fungal mycelia growing out of the sample segments were continuously subcultured and maintained on fresh PDA plates. The fungal isolates were stored in $10 \%$ glycerol at $-80^{\circ} \mathrm{C}$ for long-term storage.

\section{Identification of endophytic fungi}

The mycelial mass was scraped from the PDA plates and used to extract DNA. The mycelia were in liquid nitrogen ground using a mortar and pestle, and the fungal DNA was extracted using the DNeasy Plant Mini kit (Qiagen, Valencia, CA, USA). An internal transcribed spacer (ITS) region was amplified using the fungal specific primers, ITS1 (5'-TCCGTAGGT GAACCTGCGG-3') and ITS4 (5'-TCCTCCGCTTATTGATATGC-3') [16]. The amplification was performed in $50-\mu \mathrm{L}$ reaction volumes containing 50-150 ng of template DNA, 200 pmol of each primer, 100 pmol of each dNTP, $1.25 \mathrm{U}$ Taq DNA polymerase and $5 \mu \mathrm{L}$ polymerase chain reaction (PCR) buffer $(100 \mathrm{mM} \mathrm{KCl}, 20 \mathrm{mM} \mathrm{MgSO}, 200 \mathrm{mM}$ Tris-HCl [pH 8.8], $1 \%$ Triton X-100, $100 \mathrm{mM}\left[\mathrm{NH}_{4}\right]_{2} \mathrm{SO}_{4}$, and $1 \mathrm{mg} / \mathrm{mL}$ BSA). The PCR was performed as follows: initial denaturing step at $94^{\circ} \mathrm{C}$ for $3 \mathrm{~min}$, followed by 30 cycles of $94^{\circ} \mathrm{C}$ for $30 \mathrm{~s}, 55^{\circ} \mathrm{C}$ for $30 \mathrm{~s}$, and $72^{\circ} \mathrm{C}$ for $1 \mathrm{~min}$, and a final extension step at $72^{\circ} \mathrm{C}$ for $7 \mathrm{~min}$. The PCR products were isolated by electrophoresis on a $1.6 \%$ agarose gel and excised from the gel. The DNA was purified from the excised gel using the Wizard SV gel and PCR Clean-up System (Promega, Madison, WI, USA) and sequenced. A morphological identification was also 
conducted using the morphological characters of spores and hyphae under microscopic observation.

\section{Data analysis}

The ITS sequence information was used to match the most closely retrieved fungal isolates with the NCBI BLAST program from the GenBank database (http:// www.ncbi.nlm.nih.gov). The alignments of the ITS sequences were performed using ClustalX, and the ITS15.8S-ITS2 sequences were used to construct a phylogenetic tree with the maximum parsimony method and MEGA ver. 5 (http://www.megasoftware.net) [17,18]. Bootstrapping was performed with 1,000 replications, and gaps were removed for missing data [19]. The colonization frequency $(\mathrm{CF} \%)$ of the endophytic fungi was calculated as follows [15]: $\mathrm{CF}=\left(N_{\mathrm{COL}} / N t\right) \times 100$, where $N_{C O L}=$ the number of segments colonized by each fungus and $N t=$ the total number of segments.

\section{RESULTS}

\section{Isolation and identification of endophytic fungi}

A total of 127 fungal endophytes were isolated from 501 segments of the ginseng plants: 60 and 67 isolates from the 3- and 4-year-old ginseng plants, respectively (Table 1). The size of the PCR products ranged from 500 to $550 \mathrm{bp}$. Overall, 125 fungal isolates were assigned to 27 taxa; 19 of the 27 taxa were identified as species, and the others were classified as follows: 6 to the genus level, 1 to the phylum level (Ascomycota), and 1 as an unknown fungal isolate. A total of 13 and 19 species were detected in the 3- and 4-year-old plants, respectively. In total, the CF was $24.9 \%([125 / 501] \times 100)$, and each CF was $24.8 \%([60 / 241] \times 100)$ and $25.7 \%([67 / 260] \times 100)$

Table 1. Endophytes from R, S, P, L, and F as well as CF and IN in parentheses in 3- and 4-year-old ginseng plants cultivated in Korea

\begin{tabular}{|c|c|c|c|c|c|c|c|c|c|c|c|c|}
\hline \multirow{2}{*}{ Fungal species } & \multicolumn{5}{|c|}{3 Years old } & \multicolumn{5}{|c|}{4 Years old } & \multirow{2}{*}{ Accession no. } & \multirow{2}{*}{$\begin{array}{c}\text { Max identity } \\
(\%)\end{array}$} \\
\hline & $\mathrm{R}$ & $\mathrm{S}$ & $\mathrm{P}$ & $\mathrm{L}$ & $\mathrm{F}$ & $\mathrm{R}$ & $\mathrm{S}$ & $\mathrm{P}$ & $\mathrm{L}$ & $\mathrm{F}$ & & \\
\hline Fungal sp. & & & $4(1)$ & & & & & & $2(1)$ & $3(2)$ & GQ906971 & 100 \\
\hline Entrophospora sp. & $22(18)$ & & & & & & & & & & HM208740 & 100 \\
\hline Pythium sylvaticum & & & & & & $1(1)$ & $2(1)$ & & & & HM051065 & 100 \\
\hline Coprinopsis cinerea & & & & & & & & & & $1(1)$ & AB097562 & 99 \\
\hline Coprinellus radians & & & & & & & & $3(1)$ & & & HM595561 & 99 \\
\hline Alternaria arborescens & & & $4(1)$ & & & & & & & & AB244779 & 100 \\
\hline A. alternata & $4(3)$ & $4(2)$ & $7(2)$ & & & & $3(2)$ & & $2(1)$ & $3(2)$ & HQ647314 & 100 \\
\hline Nemania diffusa & & & & & & $1(1)$ & & & $4(2)$ & & FJ438909 & 100 \\
\hline Xylaria sp. 1 & & & & $4(2)$ & & & & $3(1)$ & $6(3)$ & & HM595549 & 100 \\
\hline Xylaria sp. 2 & & & & & & & & & $4(2)$ & & GQ906941 & 100 \\
\hline Phoma radicina & $20(16)$ & $6(3)$ & & & & $8(7)$ & & & & & FJ427058 & 100 \\
\hline Colletotrichum pisi & $5(4)$ & $2(1)$ & & & & $5(5)$ & & $3(1)$ & & & EU400150 & 100 \\
\hline C. ignotum & & & & & & & $2(1)$ & $10(3)$ & & & GU994371 & 99 \\
\hline Cladosporium sphaerospermum & & & & & & & & $3(1)$ & & & EU570258 & 100 \\
\hline Phomopsis sp. & & & & & & $2(2)$ & & & & & EF432295 & 99 \\
\hline Eutypella scoparia & & $2(1)$ & & & & & & & & & HM052827 & 100 \\
\hline Aureobasidium sp. & & & & & & & & & $2(1)$ & & GQ906942 & 93 \\
\hline Trichoderma harzianum & $1(1)$ & & & & & & & & & & FJ571487 & 100 \\
\hline Stachybotrys cylindrospora & & & & & & & $3(2)$ & & & & AF081474 & 99 \\
\hline Ascomycota sp. & & $2(1)$ & & & & & & & & & HQ108015 & 98 \\
\hline Fusarium solani & & & & & & $17(15)$ & $5(3)$ & & & & HQ384396 & 100 \\
\hline F. proliferatum & & $2(1)$ & & & & & & & & & HQ248202 & 100 \\
\hline Nectria haematococca & & & & & & $1(1)$ & $2(1)$ & & & & AB513852 & 100 \\
\hline Botryosphaeria dothidea & & & & & & & & & & $3(2)$ & HQ328038 & 100 \\
\hline Coniothyrium sp. & & & & & & & $2(1)$ & & & & AY157492 & 100 \\
\hline Monacrosporium microscaphoides & $2(2)$ & & & & & & & & & & EF059816 & 98 \\
\hline Valsa ambiens & & $2(1)$ & & & & & & & & & EU520182 & 100 \\
\hline Segments & 81 & 50 & 26 & 45 & 39 & 90 & 59 & 31 & 45 & 35 & & \\
\hline Total CF (IN) & $54(44)$ & $20(10)$ & $15(4)$ & $4(2)$ & 0 & $35(32)$ & $19(11)$ & $22(7)$ & $20(10)$ & $10(7)$ & & \\
\hline Species no. & 6 & 6 & 3 & 1 & 0 & 7 & 6 & 5 & 6 & 4 & & \\
\hline
\end{tabular}

$\mathrm{R}$, root; S, stem; P, petiole; L, leaf; F, flower stalk; CF, colonization frequencies; IN, isolate number. 
for the 3- and 4-year-old ginseng plants, respectively. The CF varied among the ages and tissues of the plants. The CFs of the roots (54\% vs. $35 \%)$ and stems $(20 \%$ vs. $19 \%$ ) in the 3-year-old plants were higher than the CFs of tissues in the 4-year-old plants (Table 1). In contrast, a higher $\mathrm{CF}$ of the petioles $(15 \%$ vs. $22 \%)$ and leaves $(4 \%$ vs. 20\%) was found in the 4-year-old plants. Whereas the $\mathrm{CF}$ of the flower stalks in the 4-year-old plants was $30 \%$, endophytic fungi were not detected in the flower stalks of the 3-year-old plants. A large proportion of the identified taxa of endophytic fungi was Ascomycota (22 species), and the others were Glomeromycota (Entrophospora sp.), Oomycota (Pythium sylvaticum), Basidiomycota (Coprinellus radians, Coprinopsis cinerea), and unclassified (fungal sp.).

\section{Dominant endophytic fungi}

The dominant endophytic fungi found to be dependant on the different age and tissue are shown in Table 2. For example, Phoma radicina and $F$. solani were the dominant endophytic fungi in the roots/stems of the 3-and 4-year-old plants, respectively, whereas $F$. solani was not found in any tissue of the 3-year-old plants. In addition, the Entrophospora genus was the dominant endophytic fungus and was only detected in the roots of the 3-yearold plants. A. alternata and C. ignotum were the dominant endophytic fungi in the petiole tissues of the 3-and 4-year-old plants, respectively. C. ignotum was only detected in the 4-year-old plants. Xylaria sp. 1 was the only fungal species detected in the leaves of the 3-yearold plants, whereas it was the dominant endophytic fungi in the leaves of the 4-year-old plants. Endophytic fungi in the flower stalks were only detected in the 4-year-old plants, with A. alternata and Botryosphaeria dothidea being the dominant endophytes.

\section{Phylogenetic tree}

The ITS sequences of the endophytic fungi were aligned using CLUSTAL X, and a phylogenetic tree was generated using the maximum parsimony method and MEGA ver. 5 (Fig. 1). The phylogenetic tree was rooted with Sclerotinia sclerotiorum and Blumeria graminis, and the numerical values at the branches indicate the percentages in the tree from 1,000 bootstrap replications. The ITS sequences of Xylaria sp. 1 and 2 showed $89 \%$ identity, whereas Xylaria sp. 1 and Nemania diffusa showed $99 \%$ identity; $N$. diffusa is an anamorph of Xylaria sp. 1. Our analysis revealed that the fungal sp. shared $77 \%$ and 90\% ITS sequence identities with Xylaria sp. 1 and 2, respectively. Therefore, Xylaria sp. 1 and 2 were divided
Table 2. Percentage contribution by the dominant endophyte (DE) to the endophytes isolated from different tissues of 3- and 4-year-old ginseng plants cultivated in Korea

\begin{tabular}{cllc}
\hline Age $(\mathrm{yr})$ & \multicolumn{1}{c}{ Tissue } & Dominant endophyte & DE $(\%)$ \\
\hline 3 & Root & Entrophospora sp. & 41 \\
& Stem & Phoma radicina & 30 \\
& Petiole & Alternaria alternata & 50 \\
& Leaf & Xylaria sp. 1 & 100 \\
& Flower stalk & None & 0 \\
4 & Root & Fusarium solani & 47 \\
& Stem & F. solani & 27 \\
& Petiole & Colletotrichum ignotum & 43 \\
& Leaf & Xylaria sp. 1 & 30 \\
& Flower stalk & Botryosphaeria dothidea & 29 \\
\hline
\end{tabular}

into two sub-clades.

\section{DISCUSSION}

A total of 127 endophytic fungi were isolated from 5 different tissues (root, stem, petiole, leaf, and flower stalk) of 3- and 4-year-old ginseng plants (Table 1). The isolated endophytic fungi were classified into 27 taxa based on their ITS sequence and morphological identification. The genera of Phoma, Collectotrichum, Alternaria, Fusarium, Entrophospora and Xlyaria were the common endophytic fungi found in the ginseng plants. Among these, Phoma, Alternaria, Fusarium and Xylaria have been found in American ginseng plants (P. quinquefolium L.) and are common endophytic fungi in tropical and subtropical plants [15]. We were unable to classify nine isolates (fungal sp.), and two isolates were classified at the phylum level (Ascomycota).

Four-year-old ginseng plants have a significantly greater diversity of endophytic fungi (13 vs. 19 species) than the 3-year-old plants. The possible explanations for this are as follows: 1) differences in the cultivation soil conditions, 2) difference in the age of the ginseng plants, and 3) regular pesticide spraying in the field of the 3-year-old ginseng plants. However, because the cultivation fields of the two different-aged plants were close to each other (less than $50 \mathrm{~m}$ ), the soil conditions may not have been very different. In American ginseng plants, the presence of endophytic fungi was dependent on the host age and type of tissue [15]: 13, 16, 15 and 11 species of endophytic fungi in 1-, 2-, 3- and 4-year-old American ginseng plants, respectively, were found. The lowest diversity of endophytic fungi was found in 4-year- 


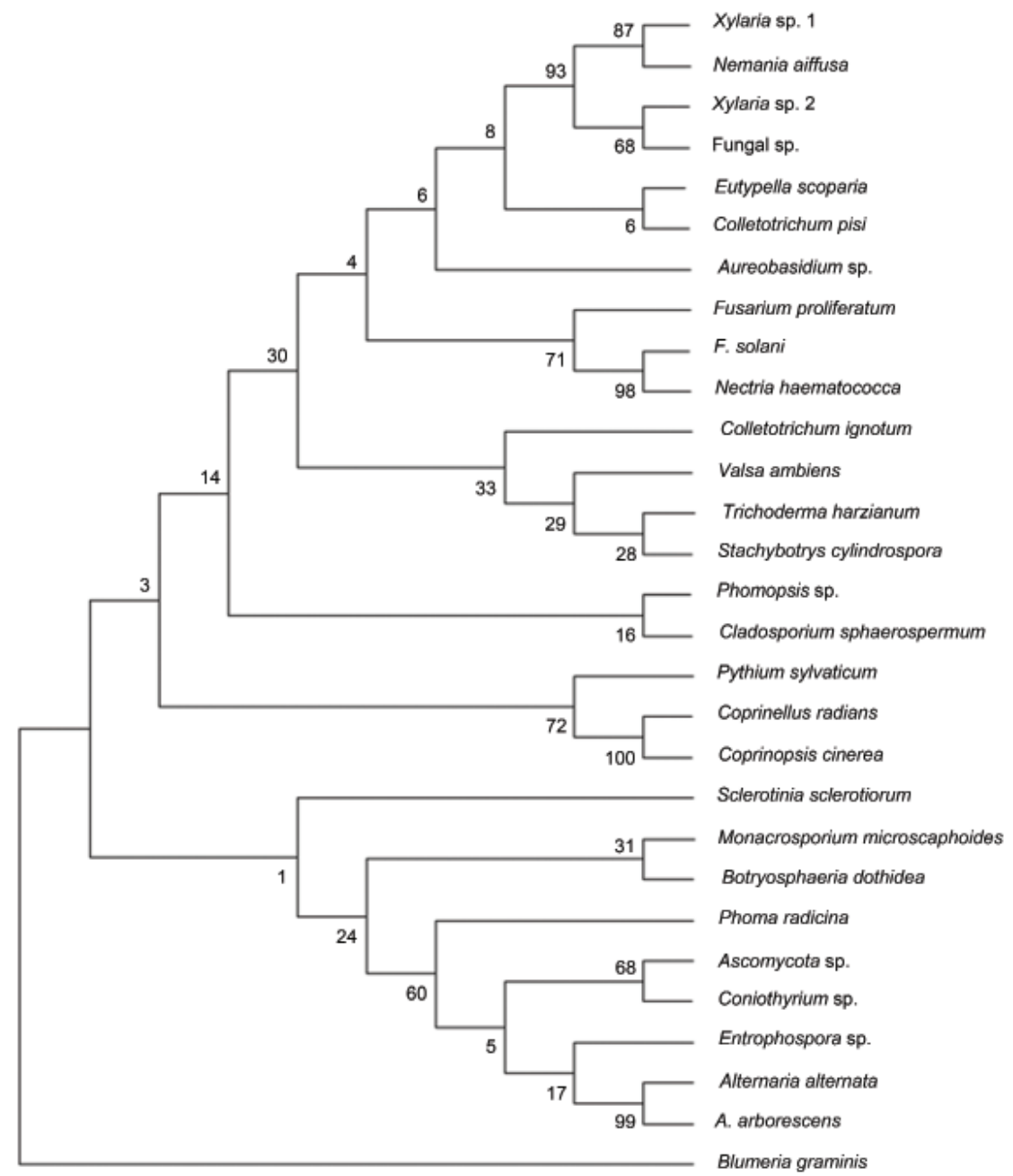

Fig. 1. Phylogenetic analysis of endophytic fungi isolated from the root, stem, petiole, leaf, and flower stalk of ginseng plants cultivated in Korea. The phylogenetic tree was constructed based on internal transcribed spacer (ITS)1-5.8S-ITS2 sequences using the maximum parsimony method on MEGA ver. 5. The percentage of replicate trees in which the associated taxa clustered together in the bootstrap test $(1,000$ replicates) is shown next to the branches. The tree is rooted with Sclerotinia sclerotiorum (AB607227) and Blumeria graminis (HM484334).

old American ginseng roots, which may be due to autotoxicity or host defense compounds in the rhizosphere [15]. Although 20 endophytic species were common to more than one age and tissue of the American ginseng, 7 species were only detected in one age or tissue. In our study, only 5 species out of 27 were common to the 3and 4-year-old plants, such as fungal sp., A. alternata, Xylaria sp. 1, Phoma radicina, and C. pisi. These results indicate the existence of age specificity of the endophytic fungi. Pesticide spraying is an alternative explanation for the significant differences observed in the diversity of the endophytic fungi, and regular spraying with chemical pesticides may have reduced the fungal population in the field of 3-year-old plants. Twenty-two Entrophospora sp. were isolated from the roots of the 3-year-old plants but not from 4-year-old plants. Many arbuscular mycorrhizae
(AM) belong to Entrophospora, which have beneficial effects on plants, and Entrophospora sp. may be more resistant to chemical pesticides compared to other fungal species. In general, pesticides significantly inhibit AM colonization and mycorrhizal spore formation [20-22], yet the inhibitory effect of pesticides on AM fungi varies with the pesticide and plant species [23]. Pesticides may also change the root hair morphology and the quality and quantity of root exudate, such as flavonoids and lectins, which have vital roles in the attraction and attachment of microorganisms to the root hairs $[24,25]$. Although pesticides inhibit the colonization of various fungi, Entrophospora sp. could survive inside the ginseng roots. Alternatively, the colonization of Entrophospora sp. on the roots may be inhibited by other fungal species not controlled by pesticides in the field of the 4-year-old plants. In other 
words, the soil environment in the cultivation field of the 3-year-old plants may favor the colonization of Entrophospora sp., and there may be a competitive environment in the cultivation field of the 4-year-old plants due to the existence of diverse fungi, suggesting the effect that pesticides may have on the diversity of endophytic fungi. The number of fungal species was much lower in the above-ground tissues of the 3-year-old plants, such as 3, 1, 0 fungal species in the petiole, leaf, and flower stalk, respectively, whereas there were 5,7 , and 4 in the 4-year-old plants (Table 1). This was additional evidence of the inhibitory effect of pesticides on the colonization of endophytes. Similar results were also observed for the $\mathrm{CF}$ : a lower $\mathrm{CF}$ was detected in the above-ground tissues of the 3-year-old plants.

AM fungi are the most common type of mycorrhizae and are ubiquitous in terrestrial ecosystems [26]. Seven genera of AM fungi have been observed based on spore morphology, which are Entrophospora, Acaulospora, Archaeospora, Glomus, Paraglomus, Gigaspora, and Scutellospora [26]. AM fungi develop a symbiotic relationship with the roots of most plants; the fungi help the plants to capture nutrients, such as phosphorus and micronutrients from the soil, enhance their environmental tolerance and inhibit pathogenic fungi, whereas the plants provide sugars to the AM fungi [27]. There are two ways to colonize the roots of the host plants, either intracellularly (AM fungi) or extracellularly (ectomycorrhizal fungi).

We also found that some fungi were dependant on the age and tissue type of the ginseng plants, and tissue specificity was reported in other plants [28-30]. In our study, Entrophospora sp. was only detected in the 3 -year-old ginseng roots, and $F$. solani was the dominant species and only observed in the roots and stems of the 4-year-old ginseng, whereas the fungus was not found in the 3-year-old ginseng. Non-pathogenic F. oxysporum strains showed disease resistance and have been used as biocontrol agents [31,32]. Xylaria sp. was the dominant species in the leaves of the 3-and 4-year-old plants (Table 1). Trichoderma harzianum, which was isolated from the 3-year-old ginseng roots, colonized roots and only survived within living plant roots [33]. T. harzianum can also antagonize other microorganisms by attacking, parasitizing and gaining nutrition from other microorganisms in plants. Trichoderma spp. have several mechanisms for the antagonization of pathogenic fungi [34].

Entophytic fungi play important roles in the ecosystem, but their significance and role in ginseng have not been explored in great detail. Entophytic fungi grow within their plant hosts without causing apparent disease symptoms and have continual metabolic interactions with their host plants [9]. Furthermore, endophytic fungi can produce phytochemicals to prevent pathogens from attacking their hosts, and some of the phytochemicals are similar to or the same as bioactive compounds found in their hosts, such as Taxol [35]. The production of bioactive compounds using microbes will provide an alternative strategy to enhance biodiversity and preserve these delicate ecosystems [11,16,32]. Endophytic fungi can also be used to protect ginseng from phytopathogens and increase the amount of ginsenosides. However, intensive research is required to identify the beneficial endophytes and to understand the comprehensive function of endophytes and their diversity in ginseng.

\section{ACKNOWLEDGEMENTS}

This work was supported by a grant from the NextGeneration Biogreen 21 Program (PJ00806302), Rural Development Administration, Republic of Korea.

\section{REFERENCES}

1. Shim MK, Lee YJ. Ginseng as a complementary and alternative medicine for postmenopausal symptoms. J Ginseng Res 2009;33:89-92.

2. Ernst E. Panax ginseng: an overview of the clinical evidence. J Ginseng Res 2010;34:259-263.

3. Nam KY. Clinical applications and efficacy of Korean ginseng (Panax ginseng C.A. Meyer). J Ginseng Res 2002;26:111-131.

4. Vuksan V, Sievenpipper J, Jovanovski E, Jenkins AL. Current clinical evidence for Korean red ginseng in management of diabetes and vascular disease: a Toronto's ginseng clinical testing program. J Ginseng Res 2010;34:264-273.

5. Yuan CS, Wang CZ, Wicks SM, Qi LW. Chemical and pharmacological studies of saponins with a focus on American ginseng. J Ginseng Res 2010;34:160-167.

6. Jin HO, Kim UJ, Yang DC. Effect of nutritional environment in ginseng field on the plant growth of ginseng (Panax ginseng C.A. Meyer). J Ginseng Res 2009;33:234-239.

7. Cho NS, Kim DH, Eom AH, Lee JW, Choi TH, Cho HY, Leonowicz A, Ohga S. Identification of symbiotic arbuscular mycorrhizal fungi in Korea by morphological and DNA sequencing features of their spores. J Fac Agric Kyushu Univ 2007;51:201-210.

8. Li TS. Evaluation of chemical and non-chemical treat- 
ments for the control of ginseng replants disease. In: International Society for Horticultural Science. Acta horticulturae 363. Leuven: International Society for Horticultural Science, 1994. p.141-146.

9. Aly AH, Debbab A, Proksch P. Fungal endophytes: unique plant inhabitants with great promises. Appl Microbiol Biotechnol 2011;90:1829-1845.

10. Schardl CL, Leuchtmann A, Spiering MJ. Symbioses of grasses with seedborne fungal endophytes. Annu Rev Plant Biol 2004;55:315-340.

11. Tan RX, Zou WX. Endophytes: a rich source of functional metabolites. Nat Prod Rep 2001;18:448-459.

12. Dang L, Li G, Yang Z, Luo S, Zheng X, Zhang K. Chemical constituents from the endophytic fungus Trichoderma ovalisprum isolated from Panax notoginseng. Ann Microbiol 2010;60:317-320.

13. Strobel G. Harnessing endophytes for industrial microbiology. Curr Opin Microbiol 2006;9:240-244.

14. Guo B, Wang Y, Sun X, Tang K. Bioactive natural products from endophytes: a review. Prikl Biokhim Mikrobiol 2008;44:153-158.

15. Xing X, Guo S, Fu J. Biodiversity and distribution of endophytic fungi associated with Panax quinquefolium L. cultivated in a forest reserve. Symbiosis 2010;51:161166.

16. Xu LL, Han T, Wu JZ, Zhang QY, Zhang H, Huang BK, Rahman K, Qin LP. Comparative research of chemical constituents, antifungal and antitumor properties of ether extracts of Panax ginseng and its endophytic fungus. Phytomedicine 2009;16:609-616.

17. Felsenstein J. Confidence limits on phylogenies: an approach using the bootstrap. Evolution 1985;39:783-791.

18. Tamura K, Dudley J, Nei M, Kumar S. MEGA4: Molecular Evolutionary Genetics Analysis (MEGA) software version 4.0. Mol Biol Evol 2007;24:1596-1599.

19. $\mathrm{Wu} \mathrm{L}$, Guo S. Interaction between an isolate of darkseptate fungi and its host plant Saussurea involucrata. Mycorrhiza 2008;18:79-85.

20. Lee LS, Sassman SA, Bischoff M, Turco RF. Degradation of N,N'-dibutylurea (DBU) in soils treated with only DBU and DBU-fortified benlate fungicides. J Environ Qual 2004;33:1771-1778.

21. O'Connor P, Manjarrez M, Smith SE. The fate and efficacy of benomyl applied to field soils to suppress activity of arbuscular mycorrhizal fungi. Can J Microbiol 2009;55:901-904.

22. Sreenivasa MN, Bagyaraj DJ. Use of pesticides for mass production of vesicular-arbuscular mychorrhizal inoculum. Plant Soil 1989;119:127-132.

23. Abd-Alla MH, Omar SA, Karanxha S. The impact of pesticides on arbuscular mycorrhizal and nitrogen-fixing symbioses in legumes. Appl Soil Ecol 2000;14:191-200.

24. Hansen AP. Symbiotic $\mathrm{N}_{2}$ fixation of crop legumes: achievement and perspectives. Weikersheim: Margraf Verlag, 1994.

25. Ratnayake M, Leonard RT, Menge JA. Root exudation in relation to supply of phosphorus and its possible relevance to mycorrhizal formation. New Phytol 1978;81:543-552.

26. Walker C, Vestberg M, Demircik F, Stockinger H, Saito M, Sawaki H, Nishmura I, Schussler A. Molecular phylogeny and new taxa in the Archaeosporales (Glomeromycota): Ambispora fennica gen. sp. nov., Ambisporaceae fam. nov., and emendation of Archaeospora and Archaeosporaceae. Mycol Res 2007;111(Pt 2):137-153.

27. Paul NC, Kim WK, Woo SK, Park MS, Yu SH. Fungal endophytes in roots of Aralia species and their antifungal activity. Plant Pathol J 2007;23:287-294.

28. Fisher PJ, Petrini O. A comparative study of fungal endophytes in xylem and bark of Alnus species in England and Switzerland. Mycol Res 1990;94:313-319.

29. Frohlich J, Hyde KD, Petrini O. Endophytic fungi associated with palms. Mycol Res 2000;104:1202-1212.

30. Ganley RJ, Newcombe G. Fungal endophytes in seeds and needles of Pinus monticola. Mycol Res 2006;110(Pt 3):318-327.

31. Postma J, Rattink H. Biological control of Fusarium wilt of carnation with a nonpathogenic isolate of Fusarium oxysporum. Can J Bot 1992;70:1199-1205.

32. Schulz B, Boyle C, Draeger S, Rommert A. K, Krohn K. Endophytic fungi: a source of novel biologically active secondary metabolites. Mycol Res 2002;106:996-1004.

33. Grondona I, Hermosa R, Tejada M, Gomis MD, Mateos PF, Bridge PD, Monte E, Garcia-Acha I. Physiological and biochemical characterization of Trichoderma harzianum, a biological control agent against soilborne fungal plant pathogens. Appl Environ Microbiol 1997;63:31893198.

34. Benitez T, Rincon AM, Limon MC, Codon AC. Biocontrol mechanisms of Trichoderma strains. Int Microbiol 2004; 7:249-260.

35. Zhao J, Shan T, Mou Y, Zhou L. Plant-derived bioactive compounds produced by endophytic fungi. Mini Rev Med Chem 2011;11:159-168. 